JMPF Vol. 9 No. 4 : 274-283

ISSN-p : 2088-8139

ISSN-e : 2443-2946

DOI : $10.22146 /$ jmpf.48024

\title{
Insidensi dan Faktor Risiko Infeksi Luka Operasi pada Bedah Obstetri dan Ginekologi di Rumah Sakit
}

\author{
Incidence and Risk Factors for Surgical Site Infections from Obstetric and Gynecological Surgeries in \\ Hospital
}

\author{
Farahdina Chairani ${ }^{1}$, Ika Puspitasari ${ }^{2 *}$, Rizka Humardewayanti Asdie ${ }^{3}$ \\ 1. Magister Farmasi Klinik, Fakultas Farmasi, Universitas Gadjah Mada,Yogyakarta \\ 2. Departemen Farmakologi \& Farmasi Klinik, Fakultas Farmasi, UGM, Yogyakarta \\ 3. Bagian IImu Penyakit Dalam, Fakultas Kedokteran UGM, RSUP Dr. Sardjito, Yogyakarta \\ Submitted: 23-07-2019 Revised: 25-09-2019 \\ Accepted: 20-12-2019
}

Korespondensi : Ika Puspitasari : Email : ika.puspitasari@gmail.com

\begin{abstract}
ABSTRAK
Infeksi Luka Operasi (ILO) merupakan salah satu tipe dari Healthcare-associated infections (HAIs) yang menyebabkan morbiditas pasca operasi. ILO banyak dilaporkan terjadi di negara berkembang dengan insidensi gabungan sebesar 11,8 kejadian dari 100 prosedur operasi. Penelitian ini bertujuan untuk mengidentifikasi faktor risiko dari ILO pada pasien yang menjalani bedah obstetri dan ginekologi di RSUP Dr. Sardjito Yogyakarta. Pengumpulan data dilakukan secara retrospektif menggunakan rekam medis pasien selama periode 1 Januari 2017-31 Desember 2018. Sebanyak total 102 pasien menjalani prosedur bedah obstetri dan ginekologi pada periode penelitian. Insidensi dari ILO pada penelitian cross sectional ini adalah 9,80\%. Bedah obstetri memiliki insidensi ILO lebih rendah dibandingkan bedah ginekologi (1,96\% versus 7,84\%). Faktor risiko dari ILO yang teridentifikasi dengan analisis bivariat adalah komorbiditas $(P=0,03)$, prosedur operasi bersamaan (OR 8,25), intraoperative blood loss $(\mathrm{OR} 0,51)$, transfusi darah perioperatif (OR 18,6), dan durasi pemberian antibiotik profilaksis (OR 1,22). Hasil analisis multivariat menunjukkan terdapat hubungan yang bermakna antara intraoperative blood loss dengan ILO (OR 0,038, Cl 95\% 0,002-0,761; $P=0,032$ ). Insidensi dan faktor risiko ILO dari penelitian retrospektif pada bedah obstetri dan ginekologi ini dapat dilaporkan secara simultan. Beberapa faktor risiko yang teridentifikasi pada penelitian ini dapat membantu stratifikasi risiko ILO di rumah sakit.
\end{abstract}

Kata kunci: antibiotic; infeksi luka operasi; healthcare associated infection

\begin{abstract}
Surgical Site Infection (SSI) is a type of Healthcare-associated infections (HAIs) which caused postoperative morbidity. SSI is widely reported in developing countries with a combined incidence of 11.8 episodes per 100 surgical procedures. This study aimed to identify risk factors for SSI in patients undergoing obstetric and gynecological surgeries at Dr. Sardjito General Hospital Yogyakarta. Data collection was conducted retrospectively using patient's medical records during the period of January 1 , 2017 to December 31, 2018. A total of 102 patients underwent obstetric and gynecological surgeries in the study period. The incidence of SSI in the cross-sectional study was $9.80 \%$. Obstetric surgeries had a lower SSI incidence compared to gynecological surgeries (1.96\% versus $7.84 \%$ respectively). The risk factors for SSI identified in the bivariate analysis were comorbidity $(P=0.03)$, concomitant surgery (OR 8.25), intraoperative blood loss (OR 0.51), perioperative blood transfusion (OR 18.6), and duration of prophylactic antibiotics (OR 1.22). The results of multivariate analysis showed a significant relationship between intraoperative blood loss and SSI (OR 0.038, CI 95\% 0.002-0.761; $P=0.032$ ). Incidence and risk factors from our retrospective study on obstetric and gynecological surgeries can be reported simultaneously. Some of the risk factors identified in this study can be helpful for SSI risk stratification in hospital.
\end{abstract}

Keywords: antibiotic; surgical site infections; health care associated infection

\section{PENDAHULUAN}

World Health Organization (WHO) melaporkan bahwa Infeksi Luka Operasi (ILO) merupakan tipe HAI (Healthcare-associated infection) yang banyak terjadi di negara berkembang dengan insidensi gabungan sebesar 11,8 kejadian dari 100 prosedur operasi ${ }^{1}$. ILO adalah infeksi pada daerah insisi atau organ-space yang terjadi pada pasien setelah pembedahan. Menurut beberapa studi, 
ILO menyebabkan peningkatan LOS (Length of Stay) di rumah sakit dari 1,5 hingga 16,6 hari. Prevalensi ILO di Indonesia diperkirakan sekitar $2,3-18,3 \%$ dan merupakan infeksi nosokomial yang paling umum terjadi, terhitung sebesar $38 \%$ dari $\mathrm{HAI}^{2,3}$.

Salah satu prosedur pembedahan yang sering dilakukan di Indonesia adalah bedah obstetri dan ginekologi. Pada bedah obstetri seperti C-section, prevalensi kejadian ILO bervariasi antara $10-20 \%$ di negara berpendapatan rendah-menengah" Sedangkan menurut data CDC (Center for Disease Control), ILO pada bedah ginekologi seperti hysterectomy terjadi sebesar $1,7 \%$ di negara maju seperti Amerika ${ }^{1}$.

Berdasarkan CDC Guideline for the Prevention of Surgical Site Infection 2017, kejadian ILO dapat dicegah hingga 50\% dengan cara memilihkan antibiotik profilaksis yang tepat dan sesuai dengan strategi evidence based $^{5}$. Menurut Anderson dkk (2014) dan Berrios-Torres dkk (2017), terdapat faktorfaktor risiko terpilih yang dapat dikaji hubungannya dengan tingkat kejadian ILO ${ }^{5,6}$. Studi-studi penelitian yang melaporkan kejadian ILO pada bedah obstetri dan ginekologi secara simultan jumlahnya masih sangat terbatas. Data tersebut diperlukan untuk meningkatkan kualitas dari suatu prosedur pembedahan dan menurunkan angka kejadian ILO. Oleh karena itu, tujuan penelitian ini yaitu untuk mengetahui insidensi dan faktor risiko terjadinya ILO pada pasien yang menjalani bedah obstetri dan ginekologi di RSUP Dr. Sardjito Yogyakarta.

\section{METODE}

\section{Rancangan Penelitian}

Penelitian ini bersifat observasional dengan rancangan analitik cross sectional yang dilakukan di RSUP Dr. Sardjito Yogyakarta pada bulan Februari-April 2019.

\section{Pengumpulan Data}

Pengumpulan data dilakukan secara retrospektif menggunakan data sekunder dari rekam medis pasien bedah obstetri dan ginekologi selama periode 1 Januari 2017-31 Desember 2018.

\section{Subyek Penelitian}

Berdasarkan perhitungan besaran sampel, jumlah minimal subyek dalam penelitian ini adalah 97 dengan tingkat kepercayaan 95\%. Kriteria inklusi dalam penelitian ini adalah pasien wanita dengan usia $\geq 18$ tahun dan mendapatkan antibiotik profilaksis untuk pembedahan. Kriteria eksklusinya yaitu pasien yang menjalani rawat inap kurang dari 24 jam setelah prosedur operasi, pasien yang meninggal kurang dari 3 hari setelah menjalani prosedur operasi, pasien yang memiliki infeksi di tempat lain sebelumnya seperti episiotomy dan infeksi jahitan operasi, dan pasien dengan rencana pemasangan implan. Penelitian ini telah memperoleh izin dari komisi etik Fakultas Kedokteran Universitas Gadjah Mada.

\section{Jenis Prosedur Pembedahan}

Jenis prosedur bedah obstetri yang termasuk dalam penelitian adalah cesarean section dan untuk prosedur bedah ginekologi yaitu vaginal hysterectomy, abdominal hysterectomy, dan laparotomy.

\section{Komorbiditas}

Komorbiditas perioperatif pada penelitian ini adalah penyakit penyerta yang diderita pasien seperti hipertensi (esensial atau diinduksi kehamilan), obesitas, hipertiroid, infeksi saluran kemih, pneumonia, anemia, adanya diagnosa penyakit sistemik (ginjal, jantung, atau hati), rheumatoid arthritis, dan kanker.

\section{Analisis Statistik}

Data individu yang memenuhi kelengkapan berdasarkan kriteria inklusi dianalisis menggunakan Statistical Package for the Social Science (SPSS). Analisis bivariat (Fisher's Exact Test) digunakan untuk mengetahui hubungan antara variabel tergantung dan faktor risiko, kemudian variabel yang memiliki nilai $P<0,1$ (dengan ILO sebagai variabel outcome) dilakukan uji multivariat (regresi logistik). Hubungan dikatakan bermakna apabila nilai $P<0,05$. 


\section{HASIL DAN PEMBAHASAN} Demografi

Sebanyak total 102 pasien wanita menjalani prosedur bedah obstetri dan ginekologi dalam penelitian ini. Usia pasien berkisar antara 19 hingga 74 tahun (rata-rata \pm standar deviasi: $36,7 \pm 10,98)$. Satu pasien yang menderita ILO meninggal selama menjalani perawatan di rumah sakit akibat syok sepsis dan multiple organ failure pada periode penelitian $(1 / 102 ; 0,98 \%)$. Semua jenis pembedahan pada penelitian ini termasuk dalam kategori bersih terkontaminasi. Rata-rata durasi rawat inap post operasi pada pasien dengan ILO lebih panjang 11,70 hari dibandingkan pada pasien tanpa ILO (15,70 hari versus. 4,0 hari).

\section{Insidensi}

Insidensi ILO 10 dari 102 pasien (9,80\%). Tingkat kejadian ILO pada bedah obstetri lebih rendah dibandingkan dengan bedah ginekologi $(2 / 102 ; 1,96 \%$ vs $8 / 102 ; 7,84 \%)$. Semua pasien ILO menjalani pemeriksaan mikrobiologi dengan hasil Enterobacter cloacae ssp cloacae (subyek 1), Pseudomonas aeruginosa (subyek 2), Enterobacter aerogens (subyek 12), Proteus mirabilis (subyek 36), Escherichia coli (subyek 37, 44 dan 57), Klebsiela pneumonia ssp pneumonia dan Enterobacter faecalis (subyek 43), E. cloacae ssp cloacae dan Citrobacter freundii (subyek 62) serta Staphylococcus aureus (subyek 4).

\section{Faktor Risiko}

Analisis Bivariat

Pasien yang memiliki komorbiditas beresiko terkena ILO dibandingkan pasien tanpa komorbiditas $(P=0,03)$. Prosedur operasi bersamaan memiliki risiko yang lebih tinggi untuk terjadinya ILO (OR 8,25). Pasien dengan intraoperative blood loss $>1500 \mathrm{~mL}$ memiliki risiko lebih besar terkena ILO dibandingkan dengan pasien yang kehilangan volume darah intraoperatif $\leq 1500 \mathrm{~mL}$ (OR 18,6). Odds ratio dari ILO hampir 4 kali lebih tinggi pada pasien yang menerima transfusi darah perioperatif dibandingkan pasien yang tidak menerima transfusi darah perioperatif. Durasi pemberian antibiotik profilaksis $>24$ jam memiliki risiko terjadinya ILO lebih besar dibandingkan dengan durasi pemberian $\leq 24$ jam.

\section{Analisis Multivariat}

Hasil yang diperoleh dari analisis multivariat (Tabel IV) menunjukkan bahwa terdapat peningkatan risiko ILO sebanyak 32 kali lipat pada pasien yang kehilangan volume darah intraoperatif $>1500$ (OR 0,038, CI 95\%, $0,002-0,761 ; \mathrm{P}=0,02$ ).

\section{Diskusi}

Sebuah studi cohort pada wanita yang menjalani bedah C-Section di perbatasan ThaiMyanmar menunjukkan bahwa tingkat kejadian ILO sebesar 5,9\%7. Penelitian lain di Tanzania melaporkan dari 774 pasien yang menjalani bedah C-Section, insidensi ILO tercatat sebesar $10,9 \%{ }^{8}$. Sedangkan studi di India menunjukkan insidensi ILO yang serupa dengan hasil penelitian ini yaitu $1,23 \%$ pada bedah obstetri. Salah satu alasan rendahnya insidensi ILO pada penelitian ini kemungkinan karena kategori kelas operasi yang termasuk hanya kelas operasi bersih terkontaminasi. Pasien yang menjalani bedah kotor atau terkontaminasi memiliki peningkatan risiko hampir tiga kali lipat terkena ILO dibandingkan bedah tidak terkontaminasi ${ }^{1}$.

Bedah ginekologi menunjukkan insidensi ILO yang lebih tinggi dibandingkan bedah obstetri. Pada rute abdominal hysterectomy, tingkat kejadian ILO lebih tinggi dibandingkan rute vaginal hysterectomy ${ }^{1}$. Hasil tersebut serupa dengan penelitian yang dilakukan oleh Lake dkk (2013) di Amerika Serikat bahwa rute vaginal hysterectomy lebih direkomendasikan karena tingkat kejadian ILO superfisial dalam 30 hari post operasi lebih rendah dibandingkan rute laparotomy 4 .

Kehamilan di usia muda merupakan faktor risiko terjadinya ILO setelah bedah CSection. Pasien dengan usia $>40$ tahun memiliki faktor risiko terkena ILO 2,95 kali lebih besar dibandingkan usia 25-40 tahun pada bedah obstetri dan ginekologi ${ }^{1}$. Namun, pada penelitian kami tidak terdapat hubungan 
Farahdina Chairani, et al

Tabel Ia. Karakteristik Pasien Bedah Obstetri dan Ginekologi $(n=102)$

\begin{tabular}{|c|c|}
\hline Karakteristik Pasien & Jumlah n (\%) \\
\hline \multicolumn{2}{|l|}{ Usia } \\
\hline$\leq 25$ Tahun & $12(11,8)$ \\
\hline$>25$ - 40 Tahun & $64(62,7)$ \\
\hline$>40$ Tahun & $26(25,5)$ \\
\hline \multicolumn{2}{|c|}{ Indeks Massa Tubuh (IMT) } \\
\hline$<18,5$ & $2(1,96)$ \\
\hline $18,5-24,9$ & $35(34,31)$ \\
\hline $25-29,9$ & $31(30,4)$ \\
\hline$\geq 30$ & $34(33,3)$ \\
\hline \multicolumn{2}{|l|}{ Komorbiditas } \\
\hline Ada & $71(69,6)$ \\
\hline Tidak ada & $31(30,4)$ \\
\hline \multicolumn{2}{|c|}{ Prosedur operasi bersamaan } \\
\hline $\mathrm{Ya}$ & $57(55,9)$ \\
\hline Tidak & $45(44,1)$ \\
\hline \multicolumn{2}{|l|}{ Operasi cito } \\
\hline Ya & $50(49)$ \\
\hline Tidak & $52(51)$ \\
\hline \multicolumn{2}{|l|}{ Tipe anestesi } \\
\hline General & $27(26,5)$ \\
\hline Lokal & $75(73,5)$ \\
\hline \multicolumn{2}{|l|}{ Skor ASA } \\
\hline $1-2$ & $88(82,2)$ \\
\hline $3-5$ & $14(13,1)$ \\
\hline \multicolumn{2}{|l|}{ Durasi Operasi } \\
\hline$<1$ jam & $14(13,7)$ \\
\hline $1-4$ jam & $86(84,3)$ \\
\hline$>4$ jam & $2(2)$ \\
\hline \multicolumn{2}{|c|}{ Intraoperative blood loss } \\
\hline$\leq 1500 \mathrm{ml}$ & $94(92,2)$ \\
\hline$>1500 \mathrm{ml}$ & $8(7,8)$ \\
\hline \multicolumn{2}{|c|}{ Transfusi darah perioperatif } \\
\hline Ya & $39(38,2)$ \\
\hline Tidak & $63(61,8)$ \\
\hline \multicolumn{2}{|c|}{ Durasi pemberian antibiotik profilaksis } \\
\hline$\leq 24$ jam & $43(42,3)$ \\
\hline$>24$ jam & $59(58,8)$ \\
\hline \multicolumn{2}{|c|}{ Jarak pemberian antibiotik profilaksis } \\
\hline$\leq 1$ jam & $90(88,2)$ \\
\hline$>1$ jam & $12(11,8)$ \\
\hline \multicolumn{2}{|c|}{ Durasi rawat preoperasi } \\
\hline$\leq 24$ jam & $56(54,9)$ \\
\hline$>24$ jam & $46(45,1)$ \\
\hline
\end{tabular}


Tabel Ib. Karakteristik Pasien Bedah Obstetri dan Ginekologi (n= 102)

\begin{tabular}{ll}
\hline Karakteristik Pasien & Jumlah $\mathbf{n}(\mathbf{\%})$ \\
\hline Durasi rawat post operasi & \\
$0-7$ hari & $89(87,3)$ \\
$7-14$ hari & $7(6,9)$ \\
$>14$ hari & $6(5,9)$ \\
\hline
\end{tabular}

antara usia dengan kejadian ILO. Hasil tersebut serupa dengan penelitian yang dilakukan di Jimma University Specialized Hospital bahwa usia tidak memiliki hubungan signifikan terhadap ILO². Menurut Anderson dkk (2014), hubungan antara usia dengan peningkatan risiko ILO kemungkinan lebih disebabkan oleh komorbiditas atau immunosenescene ${ }^{6}$.

Prosedur operasi cito pada penelitian kami tidak berhubungan dengan ILO. Sedangkan pada penelitian lain, operasi cito dan pemberian anastesi general selama pembedahan dapat meningkatkan risiko ILO' ${ }^{1}$ Menurut Megawati dan Rahmawati (2015), jenis operasi elektif dapat mengurangi risiko ILO dikarenakan adanya pemeriksaan yang cermat sebelum pembedahan'.

Prosedur operasi bersamaan memiliki hubungan yang signifikan terhadap kejadian ILO pada penelitian ini. Hasil penelitian kami serupa dengan studi yang dilakukan oleh Pathak dkk (2017) bahwa prosedur operasi bersamaan dapat meningkatkan risiko ILO (OR 3,26) ${ }^{1}$. Hal tersebut kemungkinan disebabkan oleh kompleksitas dari pembedahan yang dilakukan jika lebih dari satu prosedur sehingga berkaitan juga dengan lamanya durasi operasi. Pada penelitian kami, durasi operasi tidak memiliki hubungan terhadap kejadian ILO. Menurut Mahdi dkk (2014), durasi operasi lebih dari 1 jam berhubungan dengan peningkatan risiko ILO pada bedah hysterectomy10. Namun pada bedah C-Section, mayoritas pembedahan dilakukan dalam waktu 1 jam.

Pada penelitian kami, tidak terdapat hubungan antara jarak pemberian antibiotik profilaksis dengan ILO. Antibiotik profilaksis bedah sebaiknya diberikan dalam waktu 60 menit sebelum insisi untuk mengoptimalkan konsentrasi obat di jaringan ${ }^{11}$. Beberapa studi menyarankan pemberian antibiotik profilaksis dalam waktu 30 menit sebelum insisi karena memiliki risiko infeksi lebih rendah ${ }^{12,13}$. Terdapat hubungan yang signifikan antara durasi pemberian antibiotik profilaksis dengan ILO pasca bedah obstetri dan ginekologi. Berdasarkan rekomendasi dari guideline, durasi pemberian antibiotik profilaksis apabila penggunaannya dilanjutkan setelah operasi seharusnya diberikan <24 jam ${ }^{11}$. Menurut Anderson dan Sexton (2018), risiko infeksi Clostridium difficile jauh lebih tinggi apabila antibiotik profilaksis tetap dilanjutkan $>24$ jam post operasi ${ }^{13}$.

Berdasarkan pedoman umum penggunaan antibiotik, lama rawat inap 3 hari atau lebih sebelum operasi akan meningkatkan kejadian ILO $^{14}$. Durasi rawat inap preoperasi yang lama akan meningkatkan risiko kontaminasi bakteri dan menurunkan daya tahan tubuh sehingga pasien lebih mudah terkena ILO'.

Pada penelitian kami, intraoperative blood loss $>1500 \mathrm{~mL}$ dan transfusi darah perioperatif merupakan faktor risiko yang signifikan terhadap kejadian ILO. Berdasarkan penelitian yang dilakukan di Ethiopia, pasien bedah obstetri dengan intraoperative blood loss $>1000 \mathrm{~mL}$ memiliki risiko 2,457 kali lebih besar terkena ILO. Pasien wanita yang menerima transfusi darah preoperatif memiliki risiko 7,7 kali lebih besar mengalami ILO dibandingkan wanita yang tidak menerima transfusi darah. Transfusi darah preoperatif merupakan prediktor kejadian ILO dengan nilai $P=0,00^{2}$.

Menurut Khan dkk (2010), insidensi ILO lebih tinggi pada pasien dengan skor ASA 
Farahdina Chairani, et al

Tabel II. Karakteristik Pasien Bedah Obstetri dan Ginekologi dengan ILO (n= 10)

\begin{tabular}{|c|c|}
\hline Karakteristik Pasien & Jumlah n (\%) \\
\hline \multicolumn{2}{|l|}{ Usia } \\
\hline$\leq 25$ Tahun & $1 / 10$ \\
\hline$>25$ - 40 Tahun & $5 / 10$ \\
\hline$>40$ Tahun & $4 / 10$ \\
\hline \multicolumn{2}{|c|}{ Indeks Massa Tubuh (IMT) } \\
\hline$<18,5$ & - \\
\hline $18,5-24,9$ & $5 / 10$ \\
\hline $25-29,9$ & $2 / 10$ \\
\hline$\geq 30$ & $3 / 10$ \\
\hline \multicolumn{2}{|l|}{ Komorbiditas } \\
\hline Ada & $10 / 10$ \\
\hline Tidak ada & - \\
\hline \multicolumn{2}{|c|}{ Prosedur operasi bersamaan } \\
\hline $\mathrm{Ya}$ & $9 / 10$ \\
\hline Tidak & $1 / 10$ \\
\hline \multicolumn{2}{|l|}{ Operasi cito } \\
\hline Ya & $4 / 10$ \\
\hline Tidak & $6 / 10$ \\
\hline \multicolumn{2}{|l|}{ Tipe anestesi } \\
\hline General & $4 / 10$ \\
\hline Lokal & $6 / 10$ \\
\hline \multicolumn{2}{|l|}{ Skor ASA } \\
\hline $1-2$ & $7 / 10$ \\
\hline $3-5$ & $3 / 10$ \\
\hline \multicolumn{2}{|l|}{ Durasi Operasi } \\
\hline$<1$ jam & $1 / 10$ \\
\hline $1-4$ jam & $7 / 10$ \\
\hline$>4$ jam & $2 / 10$ \\
\hline \multicolumn{2}{|c|}{ Intraoperative blood loss } \\
\hline$\leq 1500 \mathrm{ml}$ & $6 / 10$ \\
\hline$>1500 \mathrm{ml}$ & $4 / 10$ \\
\hline \multicolumn{2}{|c|}{ Transfusi darah perioperatif } \\
\hline $\mathrm{Ya}$ & $9 / 10$ \\
\hline Tidak & $1 / 10$ \\
\hline \multicolumn{2}{|c|}{ Durasi pemberian antibiotik profilaksis } \\
\hline$\leq 24$ jam & $7 / 10$ \\
\hline$>24$ jam & $3 / 10$ \\
\hline \multicolumn{2}{|c|}{ Jarak pemberian antibiotik profilaksis } \\
\hline$\leq 1$ jam & $9 / 10$ \\
\hline$>1$ jam & $1 / 10$ \\
\hline \multicolumn{2}{|c|}{ Durasi rawat preoperasi } \\
\hline$\leq 1$ hari & $3 / 10$ \\
\hline$>1$ hari & $7 / 10$ \\
\hline \multicolumn{2}{|c|}{ Durasi rawat post operasi } \\
\hline $0-7$ hari & $2 / 10$ \\
\hline$>7$ hari & $2 / 10$ \\
\hline
\end{tabular}


Tabel III. Analisis Bivariat Faktor Risiko ILO (n= 102)

\begin{tabular}{|c|c|c|c|c|c|}
\hline \multirow[t]{2}{*}{ Faktor Risiko } & ILO & $\begin{array}{c}\text { Tidak } \\
\text { ILO }\end{array}$ & \multirow[t]{2}{*}{$\begin{array}{c}P \\
\text { value }\end{array}$} & \multirow[t]{2}{*}{$\begin{array}{l}\text { OR (Odds } \\
\text { Ratio) }\end{array}$} & \multirow[t]{2}{*}{$\begin{array}{l}\text { Confidence Interval } \\
\text { (CI) } 95 \% \text { minimum- } \\
\text { maksimum }\end{array}$} \\
\hline & n (\%) & $\mathrm{n}(\%)$ & & & \\
\hline \multicolumn{6}{|l|}{ Usia } \\
\hline$\leq 25$ Tahun & $1(10)$ & $11(12)$ & Ref & Ref & - \\
\hline$>25$ - 40 Tahun & $5(50)$ & $59(64,1)$ & 1 & 1,073 & $0,114-10,01$ \\
\hline$>40$ Tahun & $4(40)$ & $22(23,9)$ & 1 & 0,5 & $0,050-5,026$ \\
\hline \multicolumn{6}{|l|}{ IMT } \\
\hline Normal & $5(50)$ & $30(32,6)$ & 0,305 & Ref & - \\
\hline Tidak normal & $5(50)$ & $62(67,4)$ & & 2,067 & $0,55-7,690$ \\
\hline \multicolumn{6}{|l|}{ Komorbiditas } \\
\hline Ada & $10(100)$ & $61(66,3)$ & 0,03 & - & - \\
\hline Tidak ada & - & $31(33,7)$ & & Ref & - \\
\hline \multicolumn{6}{|c|}{ Prosedur operasi bersamaan } \\
\hline Ya & $9(90)$ & $48(52,17)$ & 0,040 & 8,25 & $1,004-67,783$ \\
\hline Tidak & $1(10)$ & $44(47,83)$ & & Ref & - \\
\hline \multicolumn{6}{|l|}{ Operasi cito } \\
\hline $\mathrm{Ya}$ & $4(40)$ & $46(52,3)$ & 0,741 & 0,667 & $0,176-2,519$ \\
\hline Tidak & $6(60)$ & $42(47,7))$ & & Ref & - \\
\hline \multicolumn{6}{|l|}{ Tipe anestesi } \\
\hline General & $4(40)$ & $23(25)$ & 0,449 & 2 & $0,518-7,717$ \\
\hline Lokal & $6(60)$ & $69(75)$ & & Ref & - \\
\hline \multicolumn{6}{|l|}{ Skor ASA } \\
\hline $1-2$ & $7(70)$ & $81(88)$ & 0,138 & Ref & - \\
\hline $3-5$ & $3(30)$ & $11(12)$ & & 0,317 & $0,071-1,409$ \\
\hline \multicolumn{6}{|l|}{ Durasi operasi } \\
\hline$\leq 1$ jam & $1(10)$ & $13(14)$ & 1 & Ref & - \\
\hline$<1$ jam & 9(90) & $79(86)$ & & 0,034 & $0,079-5,783$ \\
\hline \multicolumn{6}{|c|}{ Intraoperative blood loss } \\
\hline$\leq 1500 \mathrm{ml}$ & $6(60)$ & $89(96,7)$ & 0,001 & 0,51 & $0,006-0,183$ \\
\hline$>1500 \mathrm{ml}$ & $4(40)$ & $3(3,3)$ & & Ref & - \\
\hline \multicolumn{6}{|c|}{ Transfusi darah perioperatif } \\
\hline Ya & $9(90)$ & $30(32,6)$ & & Ref & - \\
\hline Tidak & $1(10)$ & $62(67,4)$ & 0,001 & 18,6 & $2,252-153,643$ \\
\hline \multicolumn{6}{|c|}{ Durasi pemberian antibiotik profilaksis } \\
\hline$\leq 24$ jam & $7(70)$ & $36(39,13)$ & & Ref & - \\
\hline$>24$ jam & $3(30)$ & $56(60,87)$ & 0,091 & 3,63 & $0,881-14,594$ \\
\hline \multicolumn{6}{|c|}{ Jarak pemberian antibiotik profilaksis } \\
\hline$\leq 1$ jam & $9(90)$ & $81(88,04)$ & 1 & Ref & - \\
\hline$>1$ jam & $1(10)$ & $18(11,96)$ & & 1,22 & $0,141-10,596$ \\
\hline \multicolumn{6}{|c|}{ Durasi rawat pre operasi } \\
\hline$\leq 1$ hari & $3(30)$ & $53(57,6)$ & 0,179 & 0,315 & $0,077-1,297$ \\
\hline$>1$ hari & $7(70)$ & $39(42,4)$ & & Ref & - \\
\hline
\end{tabular}

Fisher's Exact Test, $P$ bermakna bila nilai $P<0,05$

2-3 dibandingkan skor ASA 1 untuk kelas operasi bersih terkontaminasi $(P=0,003)^{15}$.
Studi lain menyebutkan bahwa skor ASA $\geq 3$ meningkatkan risiko ILO sebesar 1,52 kali 
Tabel IV. Analisis Multivariat Faktor Risiko ILO

\begin{tabular}{llll}
\hline Faktor risiko & $\boldsymbol{P}$ & OR & CI 95\% \\
\hline Intraoperative blood loss & 0,032 & 038 & $0,002-0,761$ \\
\hline
\end{tabular}

pada perempuan yang menjalani pembedahan hysterectomy ${ }^{16}$. Pada bedah C-Section, skor ASA $>3$ memiliki risiko lebih tinggi 2,7 kali terhadap kejadian ILO'8.

Obesitas menjadi salah satu faktor risiko terjadinya $\mathrm{ILO}^{17}$. Pada kondisi tersebut, jaringan adiposa mengalami vaskularisasi yang buruk sehingga berefek pada menurunnya suplai oksigen di jaringan ${ }^{18}$. Pada prosedur bedah C-Section, obesitas merupakan faktor risiko terjadinya ILO predischarge (OR $\geq 1,5)$ di Nova Scotia, Kanada ${ }^{19}$. Selain obesitas, kondisi anemia pasien sebelum menjalani operasi dengan nilai hemoglobin 8,6 gram/dL dapat mempengaruhi terjadinya ILO. Proses pemulihan luka tergantung sepenuhnya pada oksigenasi, apabila level oksigen rendah akibat anemia maka dapat menghentikan atau memperlambat tahapan pemulihan luka sehingga pasien lebih rentan terkena ILO ${ }^{17}$.

Pada pasien dengan gangguan hipertensi selama kehamilan, terjadi peningkatan risiko ILO sebanyak 2,9 kali ${ }^{1}$. Kondisi hipertensi tersebut merupakan faktor risiko independen terjadinya ILO pada bedah C-Section ${ }^{20}$. Pasien dengan rheumatoid arthritis yang menerima obat penekan sistem imun untuk mengurangi perkembangan nyeri sendi dapat membuat kondisinya lebih rentan terkena ILO setelah pembedahan ${ }^{21}$.

Kanker dan pengobatannya dapat menurunkan kerja sistem imun sehingga meningkatkan risiko terjadinya ILO pada pasien onkologi. Tran dkk (2015) menyebutkan bahwa penyakit kanker stadium lanjut (III/IV) merupakan faktor independen yang berhubungan dengan kejadian ILO superfisial ${ }^{22}$. Berdasarkan penelitian yang dilakukan oleh O'Donnell dkk (2019), ILO pada bedah onkologi ginekologi memiliki prevalensi tinggi terutama bagi pasien yang menjalani laparotomy dengan insidensi 15,9\%; 10 kali lebih tinggi dibandingkan insidensi yang dilaporkan oleh NHS (National Health Service)23.

\section{KESIMPULAN}

Insidensi dan faktor risiko ILO dari penelitian retrospektif kami pada bedah obstetri dan ginekologi dapat dilaporkan secara simultan dan menjadi bagian dari praktik rutin di rumah sakit. Insidensi dari ILO pada bedah obstetri lebih rendah dibandingkan bedah ginekologi. Penelitian ini mengidentifikasi beberapa faktor risiko ILO pada bedah obstetri dan ginekologi di RSUP Dr. Sardjito Yogyakarta. Beberapa faktor risiko yang diidentifikasi dapat diubah melalui intervensi. Sehingga, beberapa faktor risiko yang teridentifikasi pada penelitian ini dapat membantu stratifikasi risiko ILO dan memprioritaskan intervensi pada negara berpendapatan rendah-menengah. Diperlukan penelitian lebih lanjut dengan sampel lebih besar yang dilakukan secara prospektif.

\section{DAFTAR PUSTAKA}

1. Pathak A., Mahadik K., Swami MB., et al., Incidence and risk factors for surgical site infections in obstetric and gynecological surgeries from a teaching hospital in rural India. Antimicrobial Resistance \& Infection Control. 2017;6(1).

2. Mamo T., Abebe TW., Chichiabellu TY., Anjulo AA. Risk factors for surgical site infections in obstetrics: a retrospective study in an Ethiopian referral hospital. Patient Safety in Surgery. 2017;11(1).

3. Muttaqien MI., Hamidy MY., Rustam RP. The Overview of Surgical Site Infection of Pasca Caesarean Section at Arifin Achmad General Hospital of Riau Province 1 January - 31 December 2014 Period. 2016;3:15.

4. Lake AG., McPencow AM., DickBiascoechea MA., Martin DK., Erekson 
EA. Surgical site infection after hysterectomy. Am J Obstet Gynecol. 2013;209(5).

5. Berríos-Torres SI., Umscheid CA., Bratzler DW., et al., Centers for Disease Control and Prevention Guideline for the Prevention of Surgical Site Infection, 2017. JAMA Surgery. 2017;152(8):784.

6. Anderson DJ., Podgorny K., BerríosTorres SI., et al., Strategies to Prevent Surgical Site Infections in Acute Care Hospitals: 2014 Update. Infection Control $\mathcal{E}$ Hospital Epidemiology. 2014;35(06):605627.

7. Assawapalanggool S., Kasatpibal N., Sirichotiyakul S., Arora R., Suntornlimsiri W., Apisarnthanarak A. The efficacy of ampicillin compared with ceftriaxone on preventing cesarean surgical site infections: an observational prospective cohort study. Antimicrobial Resistance $\mathcal{E}$ Infection Control. 2018;7(1).

8. Mpogoro FJ., Mshana SE., Mirambo MM., Kidenya BR., Gumodoka B., Imirzalioglu C. Incidence and predictors of surgical site infections following caesarean sections at Bugando Medical Centre, Mwanza, Tanzania. Antimicrobial Resistance and Infection Control. 2014;3(1):25.

9. Megawati S., Rahmawati F. EVALUATION OF THE USE OF ANTIBIOTIC PROPHYLAXIS IN SURGERY PATIENTS. JMPF. 2015;5(2):127-134.

10. Mahdi H., Goodrich S., Lockhart D., DeBernardo R., Moslemi-Kebria M. Predictors of Surgical Site Infection in Women Undergoing Hysterectomy for Benign Gynecologic Disease: A Multicenter Analysis Using the National Surgical Quality Improvement Program Data. Journal of Minimally Invasive Gynecology. 2014;21(5):901-909.

11. Bratzler DW., Dellinger EP., Olsen KM., et al., Clinical practice guidelines for antimicrobial prophylaxis in surgery. American Journal of Health-System Pharmacy. 2013;70(3):195-283.
12. World Health Organization. Global Guidelines for the Prevention of Surgical Site Infection. 2016. http://apps.who.int/iris/bitstream/hand le/10665/250680/9789241549882-

eng.pdf;jsessionid=480A0E10AA4196D CEDC5308C75232AFE?sequence=1.

Accessed April 6, 2018.

13. Anderson DJ., Sexton DJ. Antimicrobial prophylaxis for prevention of surgical site infection in adults. UpToDate. September 2018:1-35.

14. Kemenkes RI. Pedoman Umum Penggunaan Antibiotik. Peraturan Menteri Kesehatan RI Nomor 2406/Menkes/Per/XII/2011; 2011.

15. Khan M., Rooh-ul-Muqim null., Zarin M., Khalil J., Salman M. Influence of ASA score and Charlson Comorbidity Index on the surgical site infection rates. J Coll Physicians Surg Pak. 2010;20(8):506509.

16. Morgan DM., Swenson CW., Streifel KM., et al., Surgical site infection following hysterectomy: adjusted rankings in a regional collaborative. Am J Obstet Gynecol. 2016;214(2):259.e1259.e8.

17. Shenoy D., Nalluri K., Manasa C., Reddy P., Srinivasan R. A study on evaluation of risk factors and antimicrobial prophylaxis in the prevention of surgical site infection. 2019;09(2):159156.

18. Singh R., Singla P., Chaudhary U. Surgical Site Infections: Classification, Risk factors, Pathogenesis and Preventive Management. 2014;2:12.

19. Ketcheson F., Woolcott C., Allen V., Langley JM. Risk factors for surgical site infection following cesarean delivery: a retrospective cohort study. CMAJ Open. 2017;5(3):E546-E556.

20. Vallejo MC, Attaallah AF, Shapiro RE, Elzamzamy OM, Mueller MG, Eller WS. Independent risk factors for surgical site infection after cesarean delivery in a rural tertiary care medical center. $J$ Anesth. 2017;31(1):120-126. 
21. Horowitz JA., Puvanesarajah V., Jain A., et al., Rheumatoid Arthritis Is Associated with an Increased Risk of Postoperative Infection and Revision Surgery in Elderly Patients Undergoing Anterior Cervical Fusion: SPINE. 2018;43(17):E1040-E1044.

22. Tran CW., McGree ME., Weaver AL., et al., Surgical site infection after primary surgery for epithelial ovarian cancer: Predictors and impact on survival.
Gynecologic Oncology. 2015;136(2):278284.

23. O'Donnell RL., Angelopoulos G., Beirne JP., et al., Impact of surgical site infection (SSI) following gynaecological cancer surgery in the UK: a trainee-led multicentre audit and service evaluation. BMJ Open. 2019;9(1):e024853. doi:10.1136/bmjopen2018-024853. 